\begin{tabular}{|c|c|}
\hline Title: & $\begin{array}{l}\text { Dynamic control of generalized electrically excited synchronous machines using } \\
\text { predictive flux control }\end{array}$ \\
\hline Authors: & Patrick Winzer, Jan Richter, Martin Doppelbauer \\
\hline Institute: & $\begin{array}{l}\text { Karlsruhe Institute of Technology (KIT) } \\
\text { Elektrotechnisches Institut (ETI) } \\
\text { Hybrid Electric Vehicles (HEV) }\end{array}$ \\
\hline Type: & Conference Proceedings \\
\hline Published at: & $\begin{array}{l}\text { IECON } 2016 \text { - 42nd Annual Conference of the IEEE Industrial Electronics Society, } \\
\text { Florence, } 2016 \\
\text { Publisher: IEEE, Piscataway (NJ) } \\
\text { Year: } 2016 \\
\text { ISBN: } 978-1-5090-3474-1 \\
\text { Pages: } 2772-2777\end{array}$ \\
\hline Hyperlinks: & DOI: https://doi.org/10.1109/IECON.2016.7793666 \\
\hline
\end{tabular}

(C) 2016 IEEE. Personal use of this material is permitted. Permission from IEEE must be obtained for all other uses, in any current or future media, including reprinting/republishing this material for advertising or promotional purposes, creating new collective works, for resale or redistribution to servers or lists, or reuse of any copyrighted component of this work in other works. 


\title{
Dynamic Control of Generalized Electrically Excited Synchronous Machines Using Predictive Flux Control
}

\author{
Patrick Winzer, Jan Richter, Martin Doppelbauer \\ Karlsruhe Insitut of Technology (KIT) \\ 76128 Karlsruhe, Germany \\ patrick.winzer@kit.edu
}

\begin{abstract}
This paper presents a novel control scheme for any kind of electrically or hybrid excited synchronous machine with an additional rotor excitation winding. Using a generalized machine model, the proposed method offers highly dynamic and precise machine control. The theoretical background on this approach as well as measurement results of a hybrid excited machine prototype with displaced reluctance axis are given in this paper. Using this method, the inversion of the torque by inverting the excitation current is executed within $70 \mathrm{~ms}$.
\end{abstract}

\section{IntRoduction}

For decades, electrically excited synchronous machines (EESMs) have been almost exclusively used as generators, directly feeding the grid. With the development of voltage source inverters and recently emerging applications such as electric traction drives, the EESM has conquered new domains [1], [2] as it offers benefits like greater safety and better torque characteristics compared to permanent magnet synchronous machines (PMSMs).

To improve efficiency, hybrid synchronous machine (HSM) concepts using both permanent magnets and electric current to excite the rotor field have been developed [3]. For further improvement, a concept additionally incorporating a displaced reluctance axis (HSM/DRA) which utilizes the reluctance torque more efficiently and therefore yields further improvements regarding torque and efficiency has been developed in [4], based on theoretical studies [5] and practical considerations [6]. A geometry of this kind of machines is depicted in Fig. 1.

A literature review reveals that numerous control methods have been developed for synchronous machines. Different machine quantities (current, flux, torque, speed or angle) are controlled using miscellaneous methods (e.g. linear, hysteresis, fuzzy logic, sliding mode, predictive) [7], [8]. Recently, finite control set model predictive torque control (FCS-MPTC) [9] and dead-beat direct torque and flux control (DB-DTFC) [10] attract further interest in permanent magnet synchronous machine control.

Due to the non-constant rotor excitation, these schemes cannot be applied to EESM directly. Thus, control methods have been developed for the EESM and the HSM. While classic PI controllers for the three axes (i.e. d-, q- and faxis) are widely applied to both types [1], [2], [11], [12], various other concepts have been evaluated for EESM, like

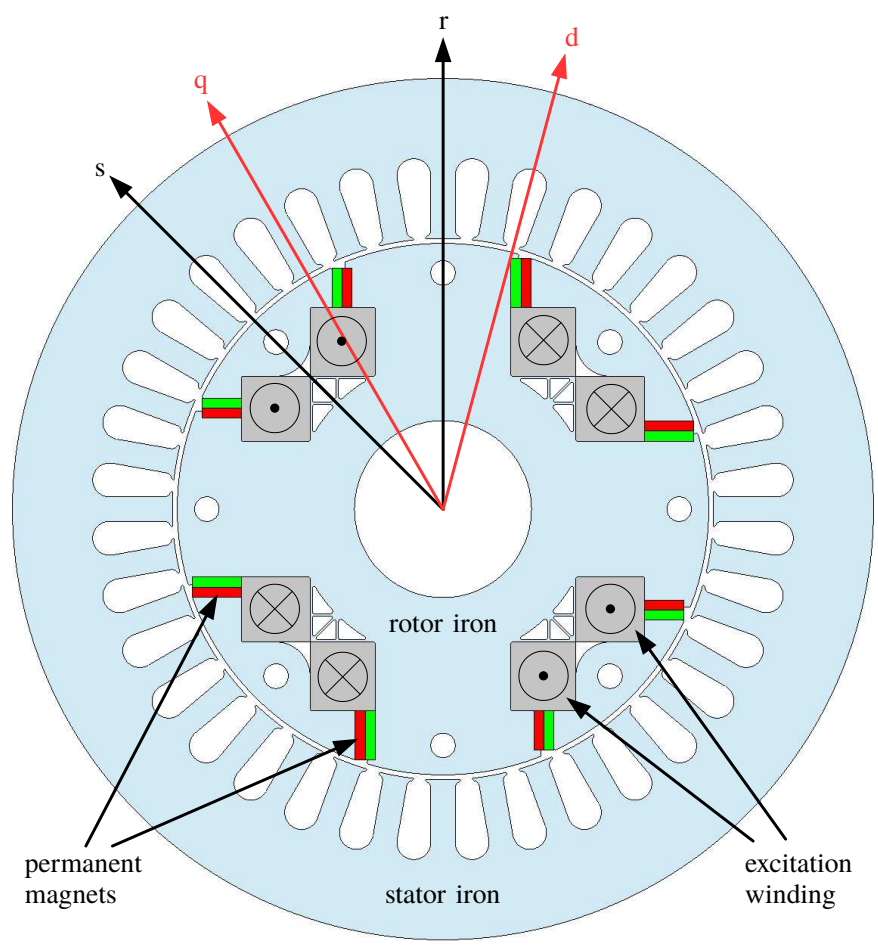

Figure 1. Geometry of the HSM/DRA. The d axis is aligned to the resulting rotor field (PM and electric excitation), the $r$ axis is aligned to the path of the lowest reluctance [4].

linear quadratic regulators [13], sliding mode controllers [14], a mixture of I and PI controllers which are transformed in stator flux coordinates [15], backstepping nonlinear control [16] or model predictive control [17].

However, the aforementioned methods suffer from two shortcomings. The first relates to the fact that modern machine concepts yield highly nonlinear magnetics to achieve high values of utilization, which is challenging for conventional controllers. As is shown in [18] for permanent magnet synchronous machines, it is necessary to consider the entirety of nonlinear magnetics such as iron and cross-saturation in order to be able to precisely control a machine and to avoid overcurrents and instabilities. It is proposed to set up the machine equations directly by using the flux linkages as 

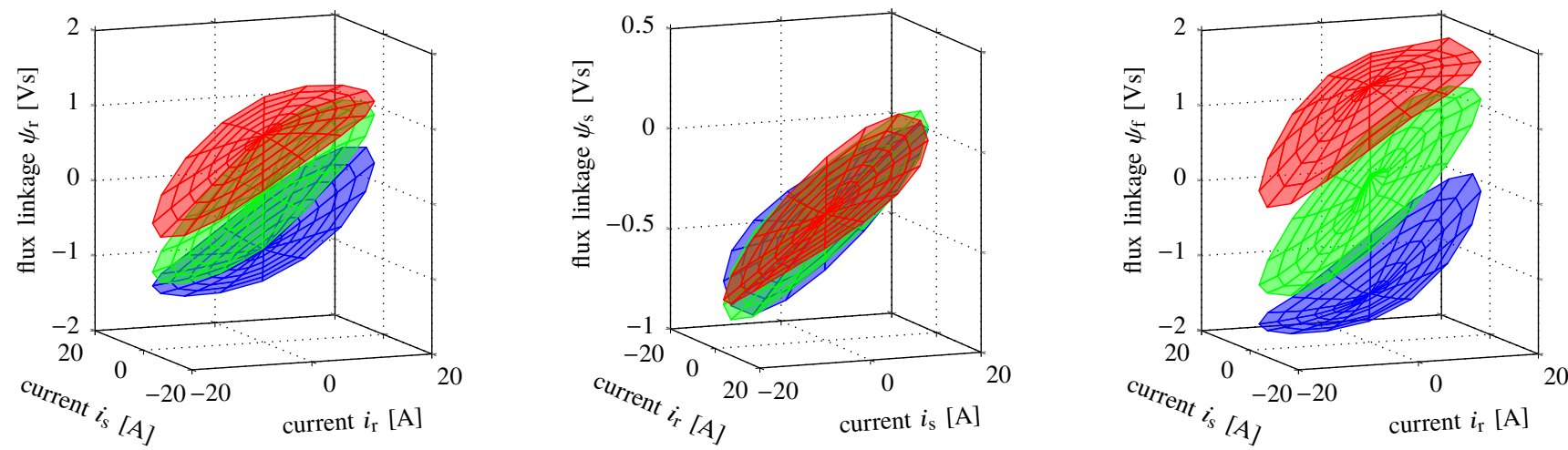

Figure 2. Measured flux linkages $\psi_{\mathrm{r}}(\mathrm{left}), \psi_{\mathrm{s}}$ (middle) and $\psi_{\mathrm{f}}($ right $)$ of the HSM/DRA prototype at $i_{\mathrm{f}}=-13 \mathrm{~A}(\mathrm{blue}), i_{\mathrm{f}}=0 \mathrm{~A}(\mathrm{green})$ and $i_{\mathrm{f}}=+13 \mathrm{~A}($ red) .

opposed to introducing inductances (either constant or current dependent) to avoid inaccuracies of the machine model.

The second drawback is that conventional controllers such as the PI-controller yield poorer dynamics compared to predictive controllers [19]. Regarding EESMs, this is of major concern as the inductance of the rotor winding is often much greater than the stator inductance [13], [14]. To achieve a change of flux in the direct rotor axis, a much greater $\int u \mathrm{~d} t$ value has to be applied to the rotor as opposed to the stator, which dramatically decreases dynamic performance. Further, the maximum applicable rotor voltage is often lower than the maximum stator voltage.

This is especially relevant for EESMs of the HSM/DRA kind, because they require an inversion of the excitation current in order to switch from maximum motoring to maximum generating torque [4]. It is therefore desirable to apply a controller which is able to establish the desired flux linkages as fast as possible.

This contribution adapts the proposed predictive controller published in [18] for a generalized EESM using the direct flux linkage connection method. This means that it can be applied to any EESM, HSM and HSM/DRA as it only depends on the flux linkage functions of the stator and rotor windings. The proposed method is demonstrated on an HSM/DRA prototype, whose geometry is given in Fig. 1. It is shown that this method avoids the two mentioned shortcomings as it delivers both precise and fast control of the machine.

In Section II, the generalized EESM model is developed. The control strategy is derived in Section III and proven in Section IV using measurement data on different step load changes. Section V concludes this contribution.

\section{Machine Model}

The machine types that are discussed in this contribution are considered to incorporate a symmetric, star-connected stator winding system with the star point not connected to the inverter. Further, dielectric currents, skin and proximity effects, iron and friction losses and spatial air-gap harmonics are neglected.

Fig. 1 shows the cross section of the HSM/DRA prototype which is treated in this paper. According to [6], the rotor ori- ented reference frame consists of an $r$ axis which is aligned to the path of the lowest reluctance and an electrically orthogonal $\mathrm{s}$ axis. Therefore, the $\mathrm{r}$ axis coincides with the field winding axis. Because the orientation of the permanent magnets is perpendicular to the field winding axis, the orientation of the total rotor flux is not aligned with any of these two axes. Merely, its orientation varies with excitation current. The usage of the conventional $\mathrm{d} / \mathrm{q}$ system, which is aligned to the rotor flux, has no advantage and is therefore avoided.

As EESMs of any kind differ from PMSMs only in the rotor, stator voltage equations can be adopted from [18], where the indices $\mathrm{d}$ and $\mathrm{q}$ are replaced by $\mathrm{r}$ and $\mathrm{s}$ :

$$
\begin{aligned}
& v_{\mathrm{r}}=R_{\mathrm{S}} i_{\mathrm{r}}+\frac{\mathrm{d} \psi_{\mathrm{r}}}{\mathrm{d} t}-\omega \psi_{\mathrm{s}} \\
& v_{\mathrm{s}}=R_{\mathrm{S}} i_{\mathrm{S}}+\frac{\mathrm{d} \psi_{\mathrm{s}}}{\mathrm{d} t}+\omega \psi_{\mathrm{r}}
\end{aligned}
$$

$R_{\mathrm{S}}$ denotes the stator resistance, $t$ the time, $\omega$ the electric angular frequency and $v_{x}, i_{x}, \psi_{x}$ the voltage, current and flux linkage components of the $\mathrm{r}$ axis $(x=\mathrm{r})$ and its quadrature axis $(x=\mathrm{s})$. The voltage equation of the field winding (f) of the rotor is expressed as:

$$
v_{\mathrm{f}}=R_{\mathrm{f}} i_{\mathrm{f}}+\frac{\mathrm{d} \psi_{\mathrm{f}}}{\mathrm{d} t}
$$

Equations (1) to (3) describe the machine behaviour entirely and are dependent on two types of machine parameters, which must be known at all times in order to control a machine predictively: the resistances $R_{\mathrm{S}}$ and $R_{\mathrm{f}}$, which can be measured once and updated temperature dependently, and the flux linkage components, which are dependent on all current components:

$$
f: \mathbb{R}^{3} \rightarrow \mathbb{R}^{3},\left(i_{\mathrm{r}}, i_{\mathrm{s}}, i_{\mathrm{f}}\right) \mapsto\left(\psi_{\mathrm{r}}, \psi_{\mathrm{s}}, \psi_{\mathrm{f}}\right)
$$

Fig. 2 shows the flux linkage components $\psi_{\mathrm{r}}, \psi_{\mathrm{s}}$ and $\psi_{\mathrm{f}}$ of the HSM/DRA prototype in Fig. 1, which are plotted versus $i_{\mathrm{r}}$ and $i_{\mathrm{s}}$ for maximum and minimum rotor current. They are derived from measurements on the prototype [4] and used as lookup tables for the control algorithm.

The offset at $i_{\mathrm{r}}=i_{\mathrm{s}}=0 \mathrm{~A}$ of the $\psi_{\mathrm{r}}$ plot is caused by the rotor field winding flux and is dependent on $i_{\mathrm{f}}$. The offset of the $\psi_{\mathrm{s}}$ 


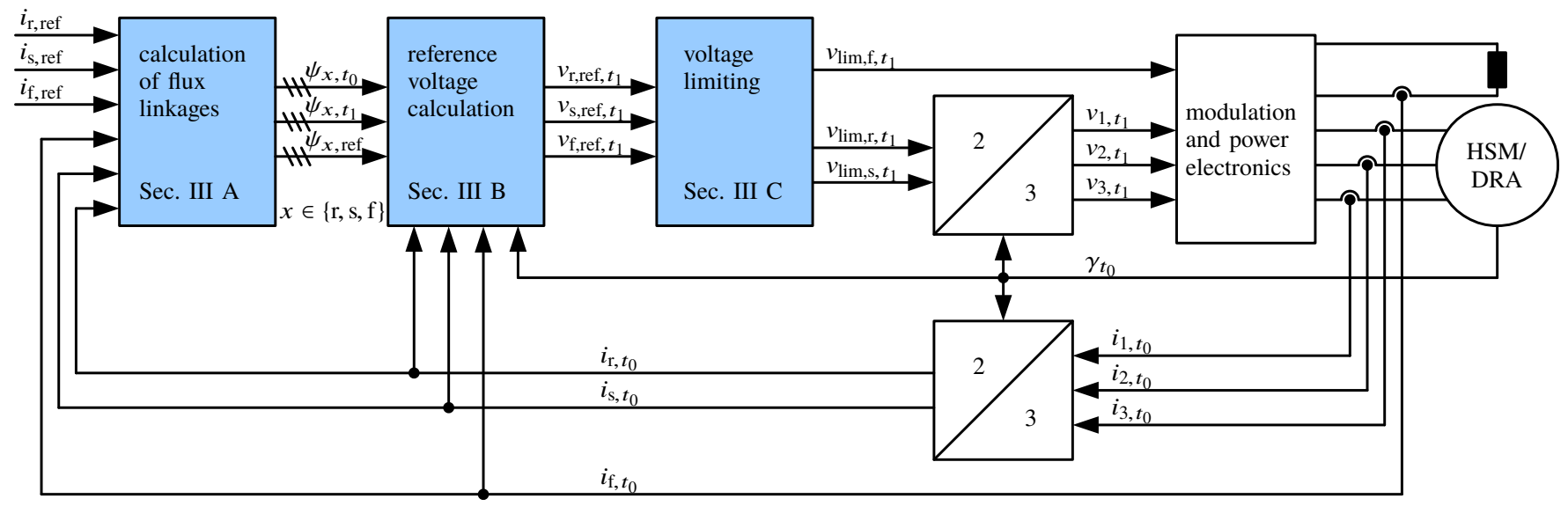

Figure 3. Block diagram of the proposed controller. The blue elements denote the controller and are described in the text.

plot originates from the permanent magnets. The flux variation in the $r$ axis is stronger because the magnetic resistance is lower due to the rotor iron core. The permanent magnets in the $\mathrm{s}$ axis increase the magnetic resistance. Further, saturation effects are evident as the curves show variable gradients in both directions. The current controller, which is described in the following section, is able to handle all these phenomena without any further adjustments.

\section{Control Strategy}

Fig. 3 shows the general control scheme, which is based on [18]. It consists of three major parts, the calculation of flux linkages, the calculation of the reference voltages and the voltage limitation. These three parts are described in the following. The generation of reference values is not considered as there are many methods published [1], [2], [13], [14].

The algorithm is of time discrete nature and executed in each control period. Its timing structure is given in Fig. 4. Within each control period, voltages $v_{x, t_{1}}$ with $x \in\{\mathrm{r}, \mathrm{s}, \mathrm{f}\}$ are calculated to be applied at the end of the control period (index $t_{1}$ ). They depend on the measured and the reference quantities at the beginning of the control period (index $t_{0}$ ).

\section{A. Calculation of Flux Linkages}

In order to obtain the voltages $v_{x, t_{1}}$ with $x \in\{\mathrm{r}, \mathrm{s}, \mathrm{f}\}$, which lead to a change of flux linkages in the time interval of $t_{1}$ to $t_{2}$, it must be known which flux linkages $\psi_{x, t_{1}}$ will be present at $t_{1}$. As $t_{1}$ is in the future while the control alorithm is active, the corresponding stator flux linkages have to be predicted [18]:

$$
\begin{aligned}
\Psi_{\mathrm{r}, t_{1}} & =\Psi_{\mathrm{r}, t_{0}}+T \frac{v_{\mathrm{r}, t_{0}}-R_{\mathrm{S}} i_{\mathrm{r}, t_{0}}+\omega_{t_{0}} \Psi_{\mathrm{s}, t_{0}}}{1+\frac{1}{4} \omega_{t_{0}}^{2} T^{2}} \\
& +T^{2} \frac{\frac{1}{2} \omega_{t_{0}} v_{\mathrm{s}, t_{0}}-\frac{1}{2} \omega_{t_{0}} R_{\mathrm{S}} i_{\mathrm{s}, t_{0}}-\frac{1}{4} \omega_{t_{0}}^{2} \Psi_{\mathrm{r}, t_{0}}}{1+\frac{1}{4} \omega_{t_{0}}^{2} T^{2}} \\
\Psi_{\mathrm{s}, t_{1}} & =\Psi_{\mathrm{s}, t_{0}}+T \frac{v_{\mathrm{s}, t_{0}}-R_{\mathrm{S}} i_{\mathrm{s}, t_{0}}-\omega_{t_{0}} \Psi_{\mathrm{r}, t_{0}}}{1+\frac{1}{4} \omega_{t_{0}}^{2} T^{2}} \\
& +T^{2} \frac{-\frac{1}{2} \omega_{t_{0}} v_{\mathrm{r}, t_{0}}+\frac{1}{2} \omega_{t_{0}} R_{\mathrm{S}} i_{\mathrm{r}, t_{0}}-\frac{1}{4} \omega_{t_{0}}^{2} \Psi_{\mathrm{s}, t_{0}}}{1+\frac{1}{4} \omega_{t_{0}}^{2} T^{2}}
\end{aligned}
$$

$T=t_{1}-t_{0}$ denotes the sampling time. The rotor flux linkage is calculated by:

$$
\Psi_{\mathrm{f}, t_{1}}=\Psi_{\mathrm{f}, t_{0}}+T\left(v_{\mathrm{f}, t_{0}}-R_{\mathrm{f}} i_{\mathrm{f}, t_{0}}\right)
$$

The flux linkages $\Psi_{x, t_{0}}$ are calculated using the measured values $i_{x, t_{0}}$ and a lookup table for the flux linkages according to equation (4). This method is also applied to calculate the desired flux linkages $\psi_{x \text {,ref }}$ at the reference currents $i_{x \text {,ref }}$.

In equations (5)-(7), the change of current within the control period must be dismissed as the current $i_{x, t_{1}}$ at the end of the control period is unknown at this state of calculations.

\section{B. Calculation of Reference Voltages}

Following the calculation of the flux linkages, equations (1) to (3) are solved in the time discrete domain using a few simplifications. To avoid the inversion of the flux linkage functions of equation (4) which is described in [18], the currents $i_{x, t_{1}}$ are replaced by the preceding values $i_{x, t_{0}}$. This reduces calculation time as well as memory in the processor. The loss of accuracy is negligible for motors of a certain size where the ohmic voltage drop is significantly lower than the other voltage components. With this simplification, the reference voltage equations are:

$$
\begin{aligned}
& v_{\mathrm{r}, \text { ref }, t_{1}}=R_{\mathrm{S}} i_{\mathrm{r}, t_{0}}+\frac{\Delta \Psi_{\mathrm{r}, \mathrm{ref}, t_{1}}}{T}-\omega_{t_{0}}\left(\Psi_{\mathrm{s}, t_{1}}+\frac{1}{2} \Delta \Psi_{\mathrm{s}, \mathrm{ref}, t_{1}}\right) \\
& v_{\mathrm{s}, \mathrm{ref}, t_{1}}=R_{\mathrm{S}} i_{\mathrm{s}, t_{0}}+\frac{\Delta \Psi_{\mathrm{s}, \text { ref }, t_{1}}}{T}+\omega_{t_{0}}\left(\Psi_{\mathrm{r}, t_{1}}+\frac{1}{2} \Delta \Psi_{\mathrm{r}, \mathrm{ref}, t_{1}}\right) \\
& v_{\mathrm{f}, \mathrm{ref}, t_{1}}=R_{\mathrm{f}} i_{\mathrm{f}, t_{0}}+\frac{\Delta \Psi_{\mathrm{f}, \mathrm{ref}, t_{1}}}{T}
\end{aligned}
$$

\begin{tabular}{|c|c|c|}
\hline $\begin{array}{c}\text { previous } \\
\text { control period }\end{array}$ & $\begin{array}{c}\text { actual } \\
\text { control period }\end{array}$ & $\begin{array}{c}\text { future } \\
\text { control period }\end{array}$ \\
\hline$t_{-1}$ & $t_{0}$ & time \\
\hline
\end{tabular}

with the reference flux linkage changes

$$
\Delta \Psi_{x, \text { ref }, t_{1}}=\Psi_{x, \text { ref }}-\Psi_{x, t_{1}} ; \quad x \in\{\mathrm{r}, \mathrm{s}, \mathrm{f}\}
$$

Figure 4. Timing diagram of the proposed controller. 


\section{Voltage Limiting}

If the predicted voltages (8)-(10) are within the voltage limits, the reference values can be reached with a dead-beat step. However, if the change in reference values is large, the stator voltage limit and the rotor voltage limit can be exceeded.

Special care has to be taken when the voltages must be limited. As the three axes are mutually coupled, a change of voltage in one axis is always visible in the other axes. That applies especially to the rotor $\mathrm{f}$ axis and the stator $\mathrm{r}$ axis, which are aligned and can be imagined as a single phase transformer. This means, if the voltage is limited in an unsuitable way (e.g. by a simple linear reduction of the voltages), an error voltage occurs which increases the current in one axis and decreases it in the other.

Therefore, it is most convenient to limit the voltages in a way that the relative changes of the flux linkage in the three axes vary by the same amount. Thus, a reduction factor $k$ is introduced:

$$
k=\frac{\Delta \Psi_{x, \text { max }, t_{1}}}{\Delta \Psi_{x, \text { ref }, t_{1}}}=\frac{\Delta \Psi_{x, \max , t_{1}}}{\Psi_{x, \text { ref }}-\Psi_{x, t_{1}}}
$$

with $x \in\{\mathrm{r}, \mathrm{s}, \mathrm{f}\}$ and $k \in] 0,1]$ where $\Delta \Psi_{x, \max , t_{1}}$ is the maximum possible flux linkage change without exceeding any voltage limit. This is conveniently accomplished by a distinction of cases:

- If only the excitation voltage exceeds its limit, the maximum possible flux linkage change $\Delta \Psi_{\mathrm{f}, \mathrm{max}, t_{1}}$ is calculated by

$$
\Delta \Psi_{\mathrm{f}, \max , t_{1}}=T\left(\operatorname{sgn}\left(v_{\mathrm{f}, \mathrm{ref}, t_{1}}\right) \cdot v_{\mathrm{f}, \max }-R_{\mathrm{f}} i_{\mathrm{f}, t_{0}}\right)
$$

with the maximum excitation voltage $v_{\mathrm{f}, \max }$ and $k$ is obtained from equations (7), (11) and (12).

- If only the stator voltage exceeds its limit, the mean stationary voltage in the period $\left[t_{1}, t_{2}\right]$ must be calculated, which will be subtracted from the total desired voltage in order to obtain the flux changing voltage components. Because the mean values of current and flux linkage in this period are unknown, the mean voltages are approximated by

$$
\begin{aligned}
& v_{\mathrm{r}, \mathrm{stat}, t_{1}}=R_{\mathrm{S}} i_{\mathrm{r}, t_{0}}-\omega_{t_{0}} \Psi_{\mathrm{s}, t_{1}} \\
& v_{\mathrm{s}, \mathrm{stat}, t_{1}}=R_{\mathrm{S}} i_{\mathrm{s}, t_{0}}+\omega_{t_{0}} \Psi_{\mathrm{r}, t_{1}}
\end{aligned}
$$

The geometric link between the points $\left(v_{\mathrm{r}, \mathrm{stat}, t_{1}}, v_{\mathrm{s}, \mathrm{stat}, t_{1}}\right)$ and $\left(v_{\mathrm{r}, \mathrm{ref}, t_{1}}, v_{\mathrm{s}, \text { ref }, t_{1}}\right)$ in the $\mathrm{r} / \mathrm{s}$ plane represents the flux changing voltage. Depending on the kind of stator voltage limitation technique, an intersection point between this line and the voltage limiting curve can be calculated. The relative distance from $\left(v_{\mathrm{r}, \mathrm{stat}, t_{1}}, v_{\mathrm{s}, \mathrm{sta}, t_{1}}\right)$ to this intersection equals $k$.

- If both voltage limits are exceeded, both of the above mentioned calculations have to be executed. The lower $k$ value must be chosen because otherwise a voltage limit would be exceeded.
Table I

Nominal Data of the HSM/DRA

\begin{tabular}{lll|ll}
\hline electrical & stator & rotor & mechanical \\
\hline line voltage & $400 \mathrm{~V}$ & $48 \mathrm{~V}$ & speed & $1400 \mathrm{~min}^{-1}$ \\
line current & $10.1 \mathrm{~A}$ & $13 \mathrm{~A}$ & power & $5.9 \mathrm{~kW}$ \\
phase resistance $\left(20^{\circ} \mathrm{C}\right)$ & $0.94 \Omega$ & $1.26 \Omega$ & torque & $40 \mathrm{Nm}$ \\
\hline
\end{tabular}

Considering the voltage limit the voltage equations are derived from (8) to (10):

$$
\begin{aligned}
& v_{\mathrm{r}, \mathrm{lim}, t_{1}}=R_{\mathrm{S}} i_{\mathrm{r}, t_{0}}+\frac{k \cdot \Delta \Psi_{\mathrm{r}, \mathrm{ref}, t_{1}}}{T}-\omega_{t_{0}}\left(\Psi_{\mathrm{s}, t_{1}}+\frac{1}{2} k \cdot \Delta \Psi_{\mathrm{s}, \mathrm{ref}, t_{1}}\right) \\
& v_{\mathrm{s}, \lim , t_{1}}=R_{\mathrm{S}} i_{\mathrm{s}, t_{0}}+\frac{k \cdot \Delta \Psi_{\mathrm{S}, \mathrm{ref}, t_{1}}}{T}+\omega_{t_{0}}\left(\Psi_{\mathrm{r}, t_{1}}+\frac{1}{2} k \cdot \Delta \Psi_{\mathrm{r}, \mathrm{ref}, t_{1}}\right) \\
& v_{\mathrm{f}, \lim , t_{1}}=R_{\mathrm{f}} i_{\mathrm{f}, t_{0}}+\frac{k \cdot \Delta \Psi_{\mathrm{f}, \mathrm{ref}, t_{1}}}{T}
\end{aligned}
$$

Special care has to be taken that the reference values are chosen in a range which ensures that the static voltage $\left(v_{\mathrm{r}, \mathrm{stat}, t_{1}}, v_{\mathrm{s}, \mathrm{stat}, t_{1}}\right)$ is located within the stator voltage limit.

\section{Measurement Results}

The algorithm is tested using various test bench measurements. The test bench consists of the HSM/DRA prototype and an EESM prototype of the same size and rating. The data of the HSM/DRA pototype are given in Table I. Both motors are mounted back-to-back via a torque meter. A photograph of the setup is given in Fig. 5

The test bench is powered by an in-house inverter and measurement system [20]. It consists of two digital signal processor (DSP) systems based on the TMS320C6748 by Texas Instruments, two modulators based on a field programmable gate array of the Cyclone series by Altera and IGBT inverters of the type FS75R12KT4 by Infineon. Torque is measured using the torquemeter DRFL-III by ETH Messtechnik, rotor speed and position are detected by two resolvers of the type RE-15-1-A15 by LTN Servotechnik. The inverter is operated at a switching frequency of $8 \mathrm{kHz}$. All calculations of the control algorithms are executed within $125 \mu \mathrm{s}$.

To demonstrate the characteristics of the controller, two measurements are presented in the following.

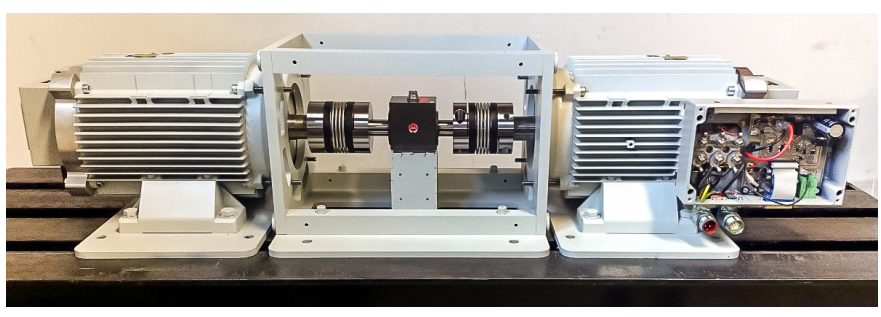

Figure 5. The HSM/DRA (left) is loaded with a conventional EESM (right) 

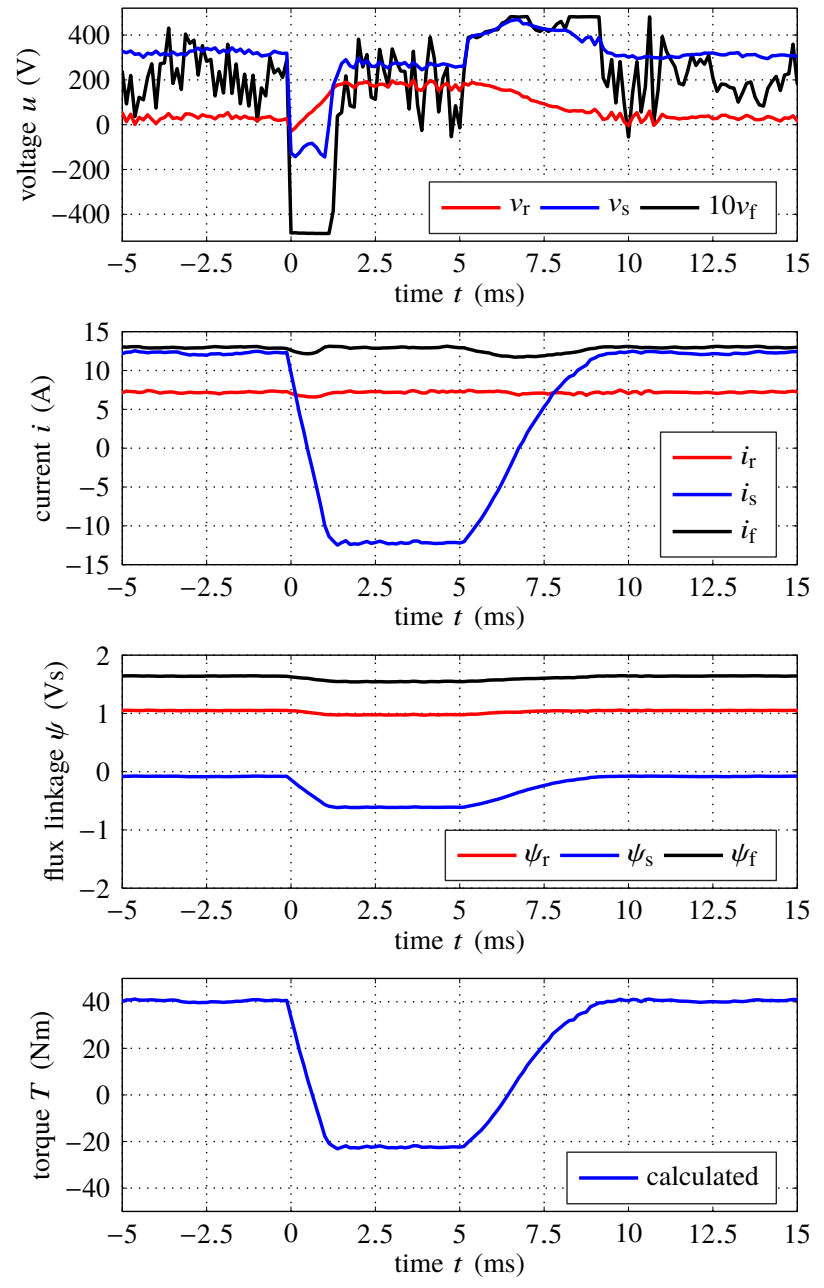

Figure 6. Twofold inversion of $i_{\mathrm{S}}$ at $n=1400 \mathrm{~min}^{-1}$. Measured torque is omitted as the torquemeter dynamics are not sufficient.

\section{A. Inversion of $i_{\mathrm{s}}$}

The first measurement is shown in Fig. 6 and demonstrates the stability and maximum dynamics of the algoithm at changes of set points which require only little changes in flux linkage. Starting at the rated operation point at $n=1400 \mathrm{~min}^{-1}$, the reference value of the s axis current $i_{\mathrm{s}}$ is inverted at $t=0 \mathrm{~ms}$ and reset to its original value at $t=5 \mathrm{~ms}$. As the HSM/DRA is magnetically asymmetric, this transition represents a change from the maximum torque $(40 \mathrm{Nm})$ to a torque value which is close to the lowest achievable with positive excitation current $(-22 \mathrm{Nm})$.

Although the $\mathrm{r}$ and $\mathrm{f}$ axis reference currents are constant, a change of flux linkages appears in these axes due to the magnetic cross-saturation. Therefore, flux-changing voltages have to be applied to all axes. At the first transition, the rotor voltage limits the maximum achievable dynamics, as the back EMF helps to decrease the $s$ axis flux linkage. The voltages are calculated to utilize the maximum available rotor voltage while maintaining a homogeneous change of flux linkage in
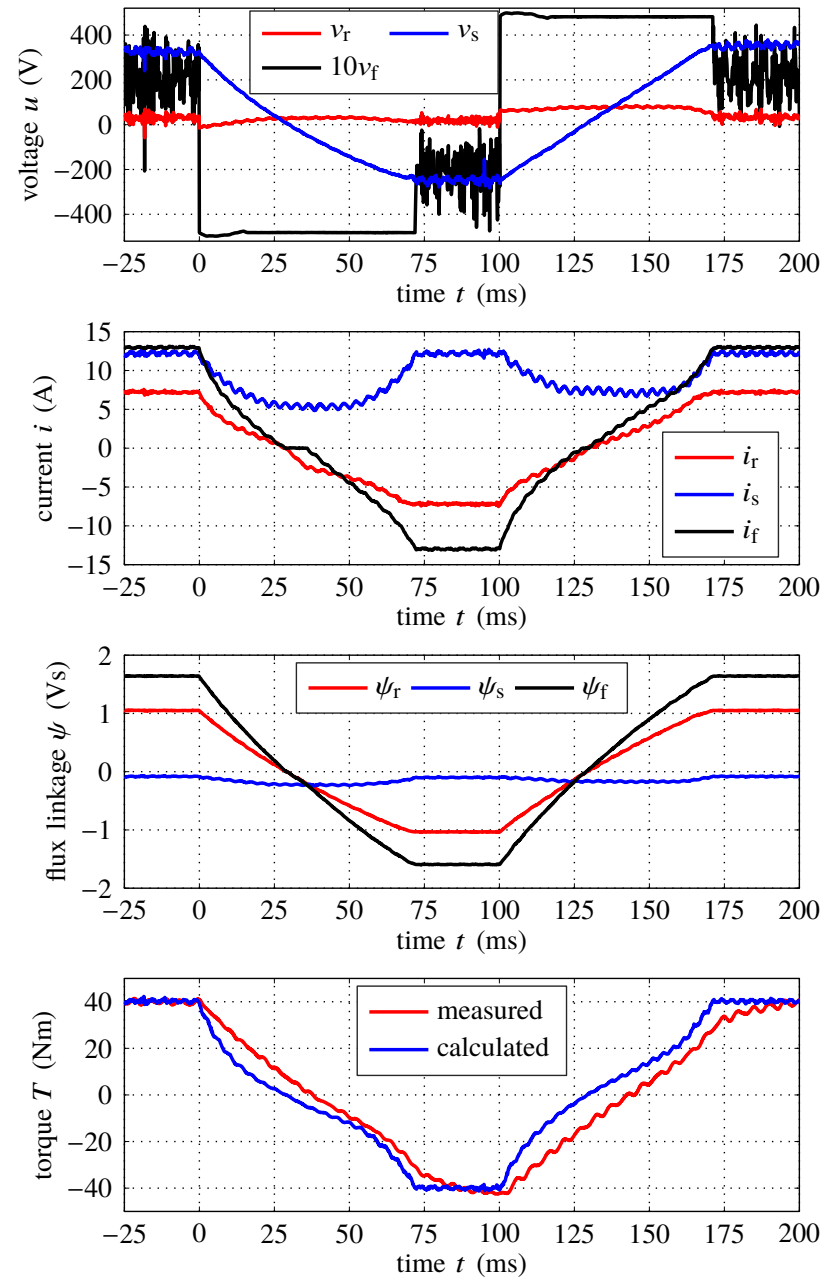

Figure 7. Twofold inversion of $i_{\mathrm{r}}$ and $i_{\mathrm{f}}$ at $n=1400 \mathrm{~min}^{-1}$.

the three axes during the whole transition, thereby ensuring maximum dynamics: This transition takes only about $1 \mathrm{~ms}$.

To increase $i_{\mathrm{S}}$ back to its original value, only a small amount of stator voltage is available. For $5 \mathrm{~ms}<t<8 \mathrm{~ms}$, the stator voltage limit is reached. As the stator voltage is limited to a hexagonal shape in the voltage plane, this manifests in a pulsating voltage trajectory with a peak at $t \approx 6.5 \mathrm{~ms}$. For $8 \mathrm{~ms}<t<9 \mathrm{~ms}$ the rotor voltage reaches its limit. This transition takes about $4 \mathrm{~ms}$.

During both transitions, the voltages are calculated in a way that the relative change of flux linkages in all three axes is equal. Due to the nonlinear relationship between currents and flux linkages, $i_{\mathrm{d}}$ and $i_{\mathrm{f}}$ may vary during the transitions. However, it is worth noticing that no overshoot in currents is present.

\section{B. Inversion of $i_{\mathrm{r}}$ and $i_{\mathrm{f}}$}

To establish the maximum generating torque of the HSM/DRA, $i_{\mathrm{r}}$ and $i_{\mathrm{f}}$ have to be inverted, requiring a large change in flux linkage. This situation is depicted in Fig. 7.

Because the rotor flux through the rotor winding has to be inverted and the rotor voltage limit is much lower than the 

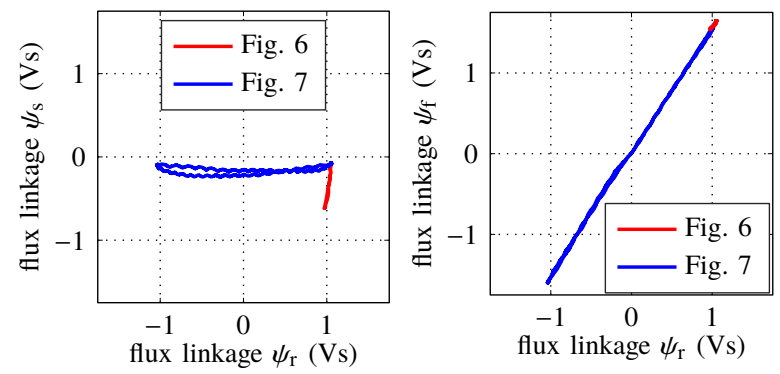

Figure 8. Flux linkage trajectories of both measurements.

stator voltage limit, the former is responsible for the dynamics in this case. During both transitions, the rotor voltage limit is reached all along. A slight overvoltage appears at the beginning of each transition because the magnetic energy flows back to the power supply. Both transitions take about $70 \mathrm{~ms}$.

A slight dip in $\psi_{\mathrm{s}}$ during the transitions is apparent, although the slope is supposed to remain constant. This is due to parameter errors in the measured flux linkage look-up tables which the controller uses. Although there is a noticeable sag in $i_{\mathrm{s}}$, again no overshoots in the current trajectories are present.

The $r$ axis and the $f$ axis show very strong magnetic coupling by definition (see Fig. 1). Put simply, the flux linkage in both axes is therefore determined by a weighted sum of $i_{\mathrm{r}}$ and $i_{\mathrm{f}}$. As the rotor voltage is bound to its limit during the transition, the controller can only vary $v_{\mathrm{r}}$ to influence both currents.

The working principle of the controller becomes clear when a different representation of the flux linkage trajectories is used. In Fig. 8, $\psi_{\mathrm{s}}$ resp. $\psi_{\mathrm{f}}$ are plotted against $\psi_{\mathrm{r}}$ for both measurements. Although the currents may vary during the transitions, the main goal of the control scheme, namely the direct control of the flux linkage, is achieved. Slight deviations appear due to parametric errors.

\section{Conclusion}

In this contribution, a model predictive control algorithm which is known from PMSMs is adapted for machines incorporating an additional rotor excitation winding. Using test bench measurements of an HSM/DRA prototype, two major benefits of this control scheme are shown. First, this method delivers excellent dynamic performance by utilizing the entire available voltage. Second, stability is ensured even at heavy load changes, which becomes evident in the absence of current overshoots or overvoltage errors. Using this method, the inversion of the torque of the HSM/DRA prototype takes only $70 \mathrm{~ms}$, which qualifies this kind of machine for applications with increased demands on dynamics such as traction drives.

\section{REFERENCES}

[1] M. Märgner and W. Hackmann, "Control challenges of an externally excited synchronous machine in an automotive traction drive application," in Emobility - Electrical Power Train, 2010, 2010, pp. 1-6.

[2] C. Rossi, D. Casadei, A. Pilati, and M. Marano, "Wound rotor salient pole synchronous machine drive for electric traction," in Industry Applications Conference, 2006. 41st IAS Annual Meeting. Conference Record of the 2006 IEEE, vol. 3, 2006, pp. 1235-1241.
[3] Y. Amara, L. Vido, M. Gabsi, E. Hoang, A. Hamid Ben Ahmed, and M. Lecrivain, "Hybrid excitation synchronous machines: Energyefficient solution for vehicles propulsion," Vehicular Technology, IEEE Transactions on, vol. 58, pp. 2137-2149, 2009.

[4] P. Winzer and M. Doppelbauer, "A hybrid permanent magnet and wound field synchronous machine with displaced reluctance axis capable of symmetric four quadrant operation," in Power Electronics and Applications (EPE'16-ECCE Europe), 18th European Conference on, 2016, accepted for publication.

[5] P. Winzer and M. Doppelbauer, "Theoretical analysis of synchronous machines with displaced reluctance axis," in Electrical Machines (ICEM), 2014 International Conference on, 2014, pp. 641-647.

[6] P. Winzer and M. Doppelbauer, "Comparison of synchronous machine designs with displaced reluctance axis considering losses and iron saturation," in Electric Machines \& Drives Conference (IEMDC), 2013 IEEE International, 2015, pp. 1801-1807.

[7] P. Cortes, M. Kazmierkowski, R. Kennel, D. Quevedo, and J. Rodriguez, "Predictive control in power electronics and drives," IEEE Transactions on Industrial Electronics, vol. 55, no. 12, pp. 4312-4324, Dec. 2008.

[8] F. Morel, X. Lin-Shi, J. Retif, B. Allard, and C. Buttay, "A comparative study of predictive current control schemes for a permanent-magnet synchronous machine drive," IEEE Transactions on Industrial Electronics, vol. 56, no. 7, pp. 2715-2728, Jul. 2009.

[9] W. Xie, X. Wang, F. Wang, W. Xu, R. Kennel, D. Gerling, and R. Lorenz, "Finite-control-set model predictive torque control with a deadbeat solution for pmsm drives," IEEE Transactions on Industrial Electronics, vol. 62, no. 9, pp. 5402-5410, Sept. 2015.

[10] J. Lee, C. Choi, J. Seok, and R. Lorenz, "Deadbeat-direct torque and flux control of interior permanent magnet synchronous machines with discrete time stator current and stator flux linkage observer," IEEE Transactions on Industry Applications, vol. 47, no. 4, pp. 1749-1758, Jul. 2011.

[11] M. Liu and X. Zhang, "Simulation of AC excitation field orientation control for hybrid excitation synchronous generator," in Measurement, Information and Control (ICMIC), 2013 International Conference on, vol. 02, 2013, pp. 879-882.

[12] R. Mbayed, G. Salloum, L. Vido, E. Monmasson, and M. Gabsi, "Hybrid excitation synchronous motor control in electric vehicle with copper and iron losses minimization," in IECON 2012 - 38th Annual Conference on IEEE Industrial Electronics Society, 2012, pp. 4886-4891.

[13] S. Carpiuc, C. Lazar, and D. Patrascu, "Optimal torque control of the externally excited synchronous machine," Journal of Control Engineering and Applied Informatics, vol. 14, no.2, pp. 80-88, 2012.

[14] A. Dòria-Cerezo, V. Utkin, R. Munoz-Aguilar, and E. Fossas, "Control of a stand-alone wound rotor synchronous generator: Two sliding mode approaches via regulation of the d-voltage component," Control Systems Technology, IEEE Transactions on, vol. 20, pp. 779-786, 2012.

[15] A. Jain and V. Ranganathan, "Modeling and field oriented control of salient pole wound field synchronous machine in stator flux coordinates," Industrial Electronics, IEEE Transactions on, vol. 58, pp. 960-970, 2011.

[16] A. El Magri, F. Giri, A. Abouloifa, and M. Haloua, "Nonlinear control of wound-rotor synchronous-motor," in Computer Aided Control System Design, 2006 IEEE International Conference on Control Applications, 2006 IEEE International Symposium on Intelligent Control, 2006 IEEE, 2006, pp. 3110-3115.

[17] M. Alnajjar and D. Gerling, "Model predictive control of six-phase variable frequency electrically excited starter generator for more electric aircraft," in Power Electronics and Drive Systems (PEDS), 2015 IEEE 11th International Conference on, 2015, pp. 23-28.

[18] J. Richter and M. Doppelbauer, "Predictive trajectory control of permanent magnet synchronous machines with nonlinear magnetics," IEEE Transactions on Industrial Electronics, vol. 63, no.6, pp. 3915-3924, 2016.

[19] J. Richter, T. Gemasmer, and M. Doppelbauer, "Predictive current control of saturated cross-coupled permanent magnet synchronous machines," in Power Electronics, Electrical Drives, Automation and Motion (SPEEDAM), 2014 International Symposium on, 2014, pp. 830-835.

[20] C. Axtmann, M. Boxriker, and M. Braun, "A custom, high-performance real time measurement and control system for arbitrary power electronic systems in academic research and education," in Power Electronics and Applications (EPE'16-ECCE Europe), 18th European Conference on, 2016, accepted for publication. 